\title{
Occurrence of Carbaryl, DDT and Deltamethrin Residues in Bovine Milk in Chhattisgarh, India and Risk Assessment to Human Health
}

\author{
Choodamani Chandrakar', Sanjay Shakya ${ }^{1}$, Tripti Jain ${ }^{2}$, S.L. Ali ${ }^{3}$, Anil Patyal ${ }^{1}$ and Praveen Kumar ${ }^{1}$ \\ ${ }^{1}$ Department of Veterinary Public Health and Epidemiology, College of Veterinary Science and Animal Husbandry, Chhattisgarh \\ Kamdhenu Vishwa Vidyalaya, Anjora, Durg (Chhattisgarh) INDIA \\ ${ }_{2}^{2}$ Animal Biotechnology Centre, Chhattisgarh Kamdhenu Vishwa Vidyalaya, Anjora, Durg (Chhattisgarh) INDIA \\ ${ }^{3}$ Department of Veterinary Medicine, College of Veterinary Science and Animal Husbandry, Chhattisgarh Kamdhenu Vishwa \\ Vidyalaya, Anjora, Durg (Chhattisgarh) INDIA
}

*Corresponding author: S Shakya; E-mail: shakyadurg@gmail.com

Received: 01 Feb., 2020

Revised: 27 March, 2020

Accepted: 29 March, 2020

\begin{abstract}
The aim of this study was to determine the occurrence of pesticide residues in bovine milk and associated health risks in human. To assess the pesticide residues, a total of 200 milk samples were analyzed using High Performance Liquid Chromatography (HPLC) with Photo Diode Array Detector (PDA).The residues of carbaryl, 4'4' DDT and deltamethrin pesticides were found in the $27.5 \%, 11 \%$ and $5 \%$ milk samples, respectively. The spatial distribution of pesticide residues in milk samples indicated that carbaryl was wide spread over the entire study area. The non-significance differences in mean residual concentrations of all three pesticides in cow and buffalo milk samples were recorded. The human health risk assessment in terms of non-carcinogenic and carcinogenic health hazard was calculated based on both lower bound [LB (mean residue levels)] and upper bound [UB ( $95^{\text {th }}$ percentile level)] limits at current levels of pesticides in bovine milk samples. The estimated average daily dietary intake (EADDI) of studied pesticides was found below the acceptable dietary intake (ADI) for both adult and children, at mean as well as $95^{\text {th }}$ percentile upper bound (UB) levels. The values suggesting lower carcinogenic and non-carcinogenic health risk to adult however children are at greater health risk.
\end{abstract}

Keywords: Bovine milk, carbaryl, deltamethrin, residues, HPLC, Chhattisgarh, lifetime cancer risk

Pesticides are extensively used in agriculture for destroying the pest of food crops and vectors of human and animal diseases, but indiscriminate use of pesticides in crop protection, food preservation and vector control has resulted into their persistence in the environment. Due to their lipophilic and highly persistent properties, these compounds can bio accumulate and bio magnify in the food chain and finally make their way into human body. Bioaccumulation of pesticides has been linked to various ill health effects such as endocrine disruption because of their capability of altering hormonal balance (Castilla-Pinedo et al., 2010). Furthermore pesticides have the potential to cause other severe health implications such as acute toxicity, long term toxic effects like cancers, reproductive and developmental disorders etc. They pose serious health risks in infants, who lack fully active enzymatic and metabolic systems (Mostafalou and Abdollahi, 2013).

The presence of pesticide residue in cow and buffalo milk is a matter of great concern to public health because milk and dairy products are extensively consumed by infants, children and adults. Pesticide residues in milk arise from contaminated feed, fodder and their direct application on dairy cattle. Since humans are on the top of the food chain, they consume the highest level of these compounds (Shaker and Elsharkawy, 2015).

Several studies has revealed that milk have pesticide

How to cite this article: Chandrakar, C., Shakya, S., Jain, T., Ali, S.L., Patyal, A. and Kumar, P. (2020). Occurrence of carbaryl, DDT and deltamethrin residues in bovine milk in Chhattisgarh, India and risk assessment to human health. J. Anim. Res., 10(2): 291-297. 
residues not only in India but in other parts of world also (Bhuvaneshwari et al., 2015). Such studies are earnestly required to monitor the pesticide residues in Chhattisgarh, India as well. Owing to paucity of such studies, it is imperative to monitor the level of pesticides in cow and buffalo milk in the state. Carbaryl and deltamethrin are among the widely used pesticides for the control of pest in crops in the Chhattisgarh. DDT is also used for vector control as Chhattisgarh is malaria prone area. Due to widespread use of these pesticides in the state, the likelihood of pesticides residues in milk is there, and lurking. Therefore, the study was conceived with the objective to investigate the occurrence of carbaryl, 4,4' DDT and deltamethrin residues in cow and buffalo milk, with an aim to assess human health risk due to exposure to these pesticides through consumption of milk.

\section{MATERIALS AND METHODS}

Pure standard of carbaryl (99.9\%), 4,4' dichlorodiphenyltrichloroethane (4, 4' DDT) (98.7\%) and deltamethrin $(99.6 \%)$, of analytical grade of PESTANAL ${ }^{\circledR}$ were procured from Sigma- Aldrich, USA. A total of 200 cow and buffalo milk samples, were randomly collected from selected dairy farms of Durg, Rajnandgaon, Raipur and Balod districts of Chhattisgarh. All the samples were collected and transported immediately to laboratory under refrigerated conditions. Milk samples were stored at $-20^{\circ} \mathrm{C}$ and analyzed within $48 \mathrm{~h}$ of collection.

\section{Extraction and cleanup of pesticide residues from milk}

Pesticide residues from milk samples were extracted as per the method described by Karabasanavar et al. (2012) with some modifications. Briefly $10 \mathrm{ml}$ milk sample was mixed with $30 \mathrm{ml}$ of acetone and methanol (1:1) mixture, homogenized for $15 \mathrm{~min}$. and centrifuged at $9744 \mathrm{~g}$ for 10 $\min$ at $4^{\circ} \mathrm{C}$. The suspension was filtered using Whatman \# 42 filter paper. The filtrate was added to $50 \mathrm{ml}$ sodium sulphate $(2.5 \%)$ and $30 \mathrm{ml}$ dichloromethane for liquidliquid extraction, followed by second time partition with $20 \mathrm{ml}$ dichloromethane. The extract was than dehydrated in sodium sulphate columns prepared in dichloromethane. To eliminate the co-extracts, the alumina chromatography was performed. The column was eluted with $15 \mathrm{ml}$ of dichloromethane and the contents were concentrated using rotatory evaporator at $40{ }^{\circ} \mathrm{C}$ until dry and final reconstitution was carried out in $2 \mathrm{ml}$ methanol. Detection and quantification of pesticide residues was done by using high performance liquid chromatography (HPLC, Waters Alliance ${ }^{\circledR}$ - e2695) with photodiode array (PDA) detector (Waters $\left.{ }^{\circledR} 2998\right)$. The wavelength $214 \mathrm{~nm}$ for carbaryl and $238 \mathrm{~nm}$ for 4, 4'DDT and deltamethrin was used for estimation of pesticide residues. The XBridge BEH C18 $(4.6 \times 250 \mathrm{~mm}, 5 \mu \mathrm{m}$ particle size $)$ column was used at $30^{\circ} \mathrm{C}$ temperature. Methanol and water $(9: 1, \mathrm{v} / \mathrm{v})$ was used as

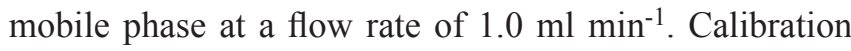
curves for carbaryl, 4, 4' DDT and deltamethrin were prepared in the range of 5-0.019 ppm, 5-0.078 ppm, $5-0.156$ ppm respectively. Limit of detection (LOD), limit of quantification (LOQ) and recovery rates were calculated to ascertain the accuracy of the results. Good linearity $\left(\mathrm{R}^{2}\right.$ $>0.999$ ) and mean recovery of carbaryl, 4, 4'DDT and deltamethrin in milk samples spiked at three different concentrations, were $87.24 \%, 72.35 \%$ and $75.45 \%$, respectively which were within acceptable recovery range of $70-120 \%$ (AOAC, 1999).

\section{Human health risk assessment}

To assess the human dietary risk from pesticides in bovine milk, data were evaluated under lower bound (LB) scenario, where undetected results were set to zero, and $95^{\text {th }}$ percentile upper bound (UB) scenario, where undetected results were set to the detection limit. The potential exposure of pesticides to humans through milk intake and related health risks, i.e. non-cancer risk and lifetime cancer risk (LCR) were estimated according to the guidelines of USEPA (USEPA, 2011). The estimated daily intake was calculated as follows:

Estimated daily intake $\left(\mathrm{mg} \mathrm{kg}^{-1}\right.$ day $\left.^{-1}\right)=$

Pesticide concentration in milk $\left(\mathrm{mg} \mathrm{kg}^{-1}\right) \times$

$\frac{\text { Milk consumption rate }\left(\mathrm{kg} \mathrm{day}^{-1}\right)}{\text { Body Weight }(\mathrm{kg})}$

The exposure was estimated on the basis of per-capita availability of milk $130 \mathrm{~g} /$ person/day in Chhattisgarh (NDDB, 2015). For evaluation of non-cancer effect from dietary pesticide exposure, the concept of hazard quotient (HQ) (= estimated daily intake/ reference dose, RfD) was used in this study. The LCR (= estimated daily intake $\times$ Oral slope factor, OSF) is presented as the increased 
probability of developing cancer over the lifetime as a result of exposure to the carcinogen. The RfD and OSF values for the carbaryl and 4, 4'DDT were acquired from the Integrated Risk Information System of USEPA (USEPA, 2009).

\section{Statistical analysis}

Statistical analysis was carried out using SPSS analytical software version 20. One-way ANOVA test using Tukey's method was applied to check the significant difference between residue levels of different pesticides in different districts of study area. A p-value of less than 0.05 was considered to be statistically significant (Bedi et al., 2015).

\section{RESULTS AND DISCUSSION}

\section{Determination of pesticide residues in milk samples and spatial distribution}

Out of 200 milk samples analyzed, 87 (43.50\%) samples were found contaminated with carbaryl, 4, 4'DDT and deltamethrin pesticide residues (Table 1). Carbaryl was present in $55(27.5 \%)$ milk samples with overall mean residual concentration of $0.028 \pm 0.003 \mu \mathrm{gml}^{-1}$, which ranged between trace and $0.287 \mu \mathrm{g} \mathrm{ml}^{-1}$. The results indicated that carbaryl contributed a greater proportion (63.21\%) followed by 4, 4'DDT (25.28\%) and deltamethrin (11.49\%). All samples positive for carbaryl and deltamethrin exceeded the MRL of $0.05 \mu \mathrm{g} / \mathrm{ml}$ and for 4, 4'DDT, 20 out of 22 positive milk samples exceeded the MRL of $0.02 \mu \mathrm{g} / \mathrm{ml}$ (Table 1). Carbaryl is the second most frequently used pesticides in Indian agriculture for control of various pests (Padhy and Shakti, 2015) and processed by formulators into over 1500 different products (Hassanzadeh et al., 2010). It is a wide-spectrum carbamate insecticide which controls more than 100 species of insects in a great variety of crops, and their residues are commonly encountered in fodder. The widespread use of carbaryl in study area led to its higher prevalence in milk samples. The residues of the carbaryl in bovine milk samples with mean residual concentration of $0.0484 \mathrm{mg} / \mathrm{ml}$ after a few weeks of its application in fodder crops was also reported (Rai et al., 2008).

The residue of 4, 4'DDT was detected in 22 (11\%) milk samples with the concentration ranged between traces and $0.276 \mu \mathrm{g} \mathrm{ml}^{-1}$. The mean residual concentration level of $4,4^{\prime}$ DDT was detected as $0.011 \pm 0.003 \mu \mathrm{g} / \mathrm{ml}$. The contamination of bovine milk with DDT and other organochlorine, pesticides has been reported from several parts of India (Battu et al., 2004; Sharma et al., 2007). The 4 , 4' DDT contamination in $8 \%$ bovine milk samples with mean concentration of $0.0550 \mu \mathrm{g} / \mathrm{ml}$ has been reported in Bundelkhand region of India (Nag and Raikwar, 2008). After ingestion, part of DDT is converted to bis[4chlorophenyl]-acetic acid (DDA) and excreted out from the human body whereas, non-metabolized DDT is stored in body fat (Rogan and Chen, 2005). The half-life of DDT is about 10-20 years and its concentration increases with age. The occurrence of 4, 4'DDT recorded in present study can be interpreted as evidence of recent exposure to DDT. Although DDT use was banned in India, but in absence of a suitable alternative of DDT for malaria control, it is still permitted for use up to 5,000 tons for vector borne disease control programs (Bedi et al., 2015).

The deltamethrin was detected in $10(5 \%)$ milk samples with mean residual concentration of $0.008 \pm 0.002 \mu \mathrm{g} /$ $\mathrm{ml}$ and ranged between traces to $0.347 \mu \mathrm{g} / \mathrm{ml}$. The contamination of milk with deltamethrin, a synthetic pyrethroids (SPs), might be due to its application on the body of the cows, its use in cow barn and milk processing

Table 1: Pesticide residues in bovine milk and their concentration $(\mu \mathrm{g} / \mathrm{ml})$

\begin{tabular}{lllllll}
\hline Pesticide & $\begin{array}{l}\text { Mean } \pm \mathbf{S E} \\
(\boldsymbol{\mu g} / \mathbf{m l})\end{array}$ & $\begin{array}{l}\text { Range of } \\
\text { pesticide }\end{array}$ & $\begin{array}{l}\text { Positive }^{\mathbf{a}} \\
\text { samples }\end{array}$ & $\boldsymbol{\%}$ Contribution $^{\mathbf{b}}$ & $\begin{array}{l}\text { Codex }^{\mathbf{c}} \\
\text { MRL }\end{array}$ & $\begin{array}{l}\text { Above } \\
\text { MRL }\end{array}$ \\
\hline Carbaryl & $0.028 \pm 0.003$ & ND- 0.287 & $55(27.5 \%)$ & $63.21 \%$ & 0.05 & $55(27.5 \%)$ \\
4,4'DDT & $0.011 \pm 0.003$ & ND- 0.276 & $22(11 \%)$ & $25.28 \%$ & 0.02 & $20(10 \%)$ \\
Deltamethrin & $0.008 \pm 0.002$ & ND- 0.347 & $10(5 \%)$ & $11.49 \%$ & 0.05 & $10(5 \%)$ \\
\hline
\end{tabular}

ND -Not detected, SE-Standard error of mean; ${ }^{a}$ percentage of positive samples out of total (200) samples analyzed; ${ }^{b}$ contribution of a particular pesticide on total detected positive samples; ${ }^{\mathrm{c}}$ maximum residue limits as per Codex Alimentarius Commission (FAO/WHO 2009). 
areas and consumption of contaminated feed, fodder and water (Goulart et al., 2008). SPs are hydrophobic compounds with log octanol-water partition coefficient $\left(\mathrm{K}_{\text {ow }}\right)$ values near to 6 and environmental persistence upto 197 days (Feo et al., 2010). SPs are also used to control pests in agriculture, homes, communities, restaurants, hospitals, and schools. Studies conducted in India have indicated the presence of residues of different SPs compound in various food commodities (Chandra et al., 2010; Sun et al., 2011). Presence of deltamethrin in 2.2\% of bovine milk samples collected from various dairy farms of Punjab was also reported (Bedi et al., 2015).

The analysis of bovine milk samples indicated that residues of carbaryl were the major contaminant (Table 2). The prevalence of carbaryl residue was highest in Raipur district (36\%) followed by Balod (32\%) Durg (22\%) and Rajnandgaon (20\%). Similarly the rate of prevalence of 4, 4' DDT residues in milk sample was highest in Raipur district (18\%) followed by Durg (10\%), Balod (10\%) and Rajnandgaon $(6 \%)$. Highest prevalence rate for deltamethrin residue was reported in Rajnandgaon district $(8 \%)$, followed by Raipur (6\%), Durg (4\%) and Balod
$(2 \%)$. The difference in residue levels of carbaryl, 4, 4' DDT and deltamethrin in all districts was statistically nonsignificant. Entire study area of the present study was a part of Chhattisgarh plane which has similar agricultural practices and possibly due to this reason significant difference in residue level of pesticides in the milk samples were not found and whatever the minor differences recorded might be due to the different management practices adopted by individual livestock owner.

\section{Species wise distribution of pesticide residues}

Prevalence pattern of carbaryl, 4, 4' DDT and deltamethrin residues was found to be similar for both cow and buffalo milk samples. Mean residual concentrations of carbaryl, 4, 4' DDT and deltamethrin detected in cow milk samples were $0.027 \pm 0.005,0.010 \pm 0.004$ and $0.007 \pm 0.003 \mu \mathrm{g} /$ $\mathrm{ml}$ respectively. Buffalo milk samples revealed mean concentration levels of $0.030 \pm 0.005,0.011 \pm 0.003$ and $0.008 \pm 0.004 \mu \mathrm{g} / \mathrm{ml}$ for carbaryl, 4, 4’ DDT and deltamethrin respectively (Table 3 ). The non-significance differences in mean residual concentrations of all three pesticides in cow and buffalo milk samples were recorded. This indicated

Table 2: Spatial distribution of pesticide residues in various districts of Chhattisgarh, India

\begin{tabular}{|c|c|c|c|c|c|c|c|c|c|}
\hline \multirow{2}{*}{$\begin{array}{l}\begin{array}{l}\text { Districts } \\
(\mathrm{n}=50 \text { for }\end{array} \\
\text { each district) }\end{array}$} & \multirow[b]{2}{*}{$\begin{array}{l}\text { Mean } \pm \text { SE } \\
(\mu \mathrm{g} / \mathrm{ml})\end{array}$} & \multicolumn{2}{|l|}{ Carbaryl } & \multicolumn{3}{|c|}{ 4,4' DDT } & \multicolumn{2}{|c|}{ Deltamethrin } & \multirow[b]{2}{*}{$\begin{array}{l}\% \\
\text { Proportion }\end{array}$} \\
\hline & & $\begin{array}{l}\% \\
\text { Positive }^{\mathrm{a}}\end{array}$ & $\begin{array}{l}\% \\
\text { Proportion }\end{array}$ & $\begin{array}{l}\operatorname{Mean} \pm \mathrm{SE} \\
(\mu \mathrm{g} / \mathrm{ml})\end{array}$ & $\begin{array}{l}\% \\
\text { Positive }^{\mathrm{a}}\end{array}$ & $\begin{array}{l}\% \\
\text { Proportion }\end{array}$ & $\begin{array}{l}\text { Mean } \pm \text { SE } \\
(\mu \mathrm{g} / \mathrm{ml})\end{array}$ & $\begin{array}{l}\% \\
\text { Positive }^{\mathrm{a}}\end{array}$ & \\
\hline Durg & $0.025 \pm 0.007$ & $11(22 \%)$ & 61.11 & $0.012 \pm 0.005$ & $5(10 \%)$ & 27.77 & $0.006 \pm 0.004$ & $2(4 \%)$ & 11.11 \\
\hline Rajnandgaon & $0.020 \pm 0.005$ & $10(20 \%)$ & 58.82 & $0.012 \pm 0.007$ & $3(6 \%)$ & 17.64 & $0.013 \pm 0.006$ & $4(8 \%)$ & 23.52 \\
\hline Raipur & $0.034 \pm 0.007$ & $18(36 \%)$ & 60.00 & $0.014 \pm 0.005$ & $9(18 \%)$ & 30.00 & $0.011 \pm 0.007$ & $3(6 \%)$ & 10.00 \\
\hline Balod & $0.036 \pm 0.009$ & $16(32 \%)$ & 72.72 & $0.004 \pm 0.002$ & $5(10 \%)$ & 22.72 & $0.002 \pm 0.002$ & $1(2 \%)$ & 4.54 \\
\hline
\end{tabular}

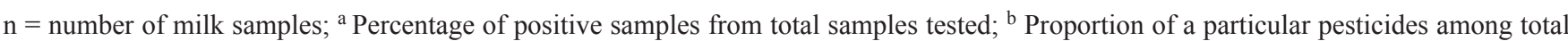
pesticide detected in each district.

Table 3: Species wise distribution of pesticide residues in bovine milk samples

\begin{tabular}{|c|c|c|c|c|c|c|c|c|}
\hline \multirow[b]{2}{*}{ Pesticide } & \multicolumn{4}{|c|}{$\operatorname{Cow}(n=100)$} & \multicolumn{4}{|c|}{ Buffalo $(n=100)$} \\
\hline & $\begin{array}{l}\text { Mean } \pm \text { SE } \\
(\mu \mathrm{g} / \mathrm{ml})\end{array}$ & Range & $\begin{array}{l}\% \\
\text { Positive }^{\mathrm{a}}\end{array}$ & $\begin{array}{l}\% \\
\text { Proportion }\end{array}$ & $\begin{array}{l}\text { Mean } \pm \text { SE } \\
(\mu \mathrm{g} / \mathrm{ml})\end{array}$ & Range & $\begin{array}{l}\% \\
\text { Positive }\end{array}$ & $\begin{array}{l}\% \\
\text { Proportion }\end{array}$ \\
\hline Carbaryl & $0.027 \pm 0.005$ & ND-0.287 & $27(27 \%)$ & 64.28 & $0.030 \pm 0.005$ & ND-0.209 & $28(28 \%)$ & 62.22 \\
\hline 4,4’ DDT & $0.010 \pm 0.004$ & ND- 0.276 & $10(10 \%)$ & 23.80 & $0.011 \pm 0.003$ & ND-0.264 & $12(12 \%)$ & 26.66 \\
\hline Deltamethrin & $0.007 \pm 0.003$ & ND-0.196 & $5(5 \%)$ & 11.90 & $0.008 \pm 0.004$ & ND-0.347 & $5(5 \%)$ & 11.11 \\
\hline
\end{tabular}

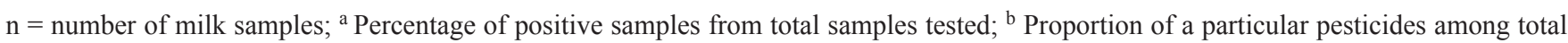
pesticide detected. 
that the consumers of both buffalo milk and cow milk are at equal risk. The pesticides included in the study are lipophilic in nature and metabolized very little in animals. Although buffalo milk has more fat content as compared to cow milk but still no difference in residue levels were detected in milk samples. In this study prevalence of carbaryl residue in cow milk was $27 \%$ which was higher than the earlier reports of $19.18 \%$ recorded in cow milk in Kumaon region of Uttrakhand, India (Rai et al., 2008). The prevalence of DDT residue in buffalo milk was $12 \%$, on contrary, significantly higher prevalence of $70 \%$ was reported in Delhi city, India (Aslam et al., 2013).

\section{Human health risk assessment}

The potential health risks were assessed based on dietary intake of pesticides residues from milk consumption. The estimated average daily dietary intake (EADDI) values of carbaryl, 4, 4' DDT and deltamethrin pesticide residues in this study were recorded lower than the recommended ADI values at both mean LB and UB levels (Table 4). Assuming the same dietary intake of milk for both children and adult, it was observed that children are at higher risk than the adults. The estimated dietary intake for carbaryl, 4, 4'DDT and deltamethrin residues remained within safe limits during this study period and are in accordance to the findings of Battu et al.(2004).

For non-cancer risk, HQ was individually calculated for carbaryl and 4, 4' DDT. The estimates revealed that HQ values for carbaryl and 4, 4' DDT were $<1$ at both the LB and UB levels which is within the acceptable limit thus pose lower chances of non-cancer risks (Table 5). However, ingestion of the milk contaminated with more than one pesticide residues may lead to more severe health hazards as a result of the synergistic effect of pesticides. The cancer risk for 4, 4' DDT exposure through dietary intake of milk at mean $\mathrm{LB}$ residue levels was 7.9E06 , which is within the recommended range of USEPA reference values. However at the 95-percentile UB level, obtained value was $1.13 \mathrm{E}-05$ which is higher than USEPA derived value thus poses higher chance of cancer risk at this concentration (Table 6). DDT and other OCPs have been classified with respect to carcinogenicity in B2-

Table 4: Estimated average daily dietary intakes of pesticides in adult and children through consumption of milk

\begin{tabular}{|c|c|c|c|c|c|}
\hline Pesticides & $\begin{array}{l}\text { ADI }(\mathrm{mg} / \mathrm{kg} \\
\text { bw/day })^{\mathrm{a}}\end{array}$ & $\begin{array}{l}\text { TADIs }(\mathrm{mg} / \mathrm{day})^{\mathrm{b}} \\
\text { for adult }\end{array}$ & $\begin{array}{l}\text { TADI }(\mathrm{mg} / \mathrm{day})^{\mathrm{c}} \\
\text { for children }\end{array}$ & $\begin{array}{l}\text { EADDI (mg) Mean LB } \\
(\mathrm{mg} / \text { day })=\text { Mean } \times 0.130 \\
(\mathrm{~kg} / \text { day })\end{array}$ & $\begin{array}{l}\text { EADDI (mg) P95_UB } \\
(\mathrm{mg} / \mathrm{Day})=\text { P95_UB } \times \\
0.130 \text { (kg/day) }\end{array}$ \\
\hline Carbaryl & 0.008 & 0.480 & 0.080 & 0.0036 & 0.0046 \\
\hline 4,4’DDT & 0.010 & 0.600 & 0.100 & 0.0014 & 0.0020 \\
\hline Deltamethrin & 0.010 & 0.600 & 0.100 & 0.0010 & 0.0016 \\
\hline
\end{tabular}

${ }^{a}$ Acceptable daily intake (ADI) obtained from Codex Alimentarius Commission; ${ }^{\mathrm{b}}$ TADI ( total ADI) value for adults:- ADI multiplied by average body weight of $60 \mathrm{~kg}$; ${ }^{\mathrm{c}}$ TADI value for children:- ADI multiplied by average body weight of $10 \mathrm{~kg}$.

Table 5: Estimation of Hazard Quotient (HQ) for adult and children at LB (mean) and UB (P95)

\begin{tabular}{|c|c|c|c|c|c|c|c|}
\hline \multirow{2}{*}{ Pesticide } & \multirow{2}{*}{$\begin{array}{l}\text { RfD (mg/kg bw/ } \\
\text { day) })^{\mathrm{a}}\end{array}$} & \multicolumn{2}{|c|}{ Adult (HQ) } & \multicolumn{2}{|c|}{ Children (HQ) } & \multicolumn{2}{|c|}{ Non Cancer Risk } \\
\hline & & Mean LB & P95_UB & Mean LB & P95_UB & Adult & Children \\
\hline Carbaryl & $1 \times 10^{-1}$ & 0.0006 & 0.0007 & 0.0036 & 0.0076 & No & No \\
\hline 4,4'DDT & $5 \times 10-4$ & 0.046 & 0.066 & 0.28 & 0.40 & No & No \\
\hline
\end{tabular}

${ }^{a} \mathrm{RfD}$ values (guidline values) obtained from USEPA.

Table 6: Estimated cancer risk associated with exposure to pesticides from milk

\begin{tabular}{llllllll}
\hline \multirow{2}{*}{ Pesticide } & $\begin{array}{l}\text { OSF } \\
(\mathbf{m g} / \mathbf{k g} / \mathbf{d a y})\end{array}$ & Mean LB & P95_UB & Mean LB & P95_UB & Adult & Children \\
\hline 4,4'DDT & 0.340 & $7.9 \mathrm{E}-06$ & $1.13 \mathrm{E}-05$ & $4.7 \mathrm{E}-05$ & $6.6 \mathrm{E}-05$ & Low & High \\
\hline
\end{tabular}

OSF (Oral slope Factor) (mg/kg/day) given by USEPA. 
class (probable human carcinogen). Results of present study are similar to the findings of Bedi et al. (2015) who reported lower non-carcinogenic and carcinogenic health risk at mean level and higher risk at 95-percentile UB level. Carbaryl and deltamethrin do not have published guideline values for estimation of carcinogenicity hence not evaluated during the present study. Findings of present study suggested that adults are not at risk from dietary exposure of carbaryl, 4,4'DDT and deltamethrin, because of lower per capita consumption of milk (130g/person/ day) and relatively low concentration of studied pesticides in milk. The presence of pesticide in the bovine milk has drawn considerable attention during recent years and concerns have been raised with quality of milk. Available literature indicated the higher residue level of chemical compounds in food as a result of environmental pollution (Bedi et al., 2015) therefore it was imperative to assess the potential of different chemical compounds for their adverse effect on public health.

\section{CONCLUSION}

Analysis of milk samples for pesticide residues in Chhattisgarh showed that carbaryl residues are predominantly present in this region followed by 4, 4' DDT and deltamethrin. The similar pattern of pesticide residues in milk samples was recorded in all four districts. The occurrence of less persistent carbaryl and deltamethrin residues in milk reflect the improper use and poor animal husbandry practices in dairy farms. Therefore, development and use of appropriate management strategies along with education of dairy farmers should be in priority to minimize the pesticide residues associated public health risks. In comparison to adults, children were at higher health risk at 95-percentile UB levels of pesticide residues in bovine milk in this region. At mean LB residue levels the cancer risk for population found to be with in the recommended range of USEPA reference values, but at the 95-percentile UB, cancer risks were found to be greater for children. On the basis of these findings, there is need of more intense and continuous monitoring of pesticide residues in milk and milk products in the region.

\section{ACKNOWLEDGMENTS}

The authors are thankful to Director of Research Chhattisgarh Kamdhenu Vishwavidyalaya Durg for providing the financial support to carry out this work.

\section{REFERENCES}

AOAC (Association of Official Analytical Chemists).1999. Guidelines for single-laboratory validation of analytical methods for trace level concentrations of organic chemicals. Available via http://www.iaea.org/trc/pest-qa

Aslam, M., Rais, S. and Alam, M. 2013. Quantification of organochlorine pesticide residues in the buffalo milk samples of Delhi city, India. J. Environ. Prot., 4(9): 964-974.

Battu, R.S., Singh, B. and Kang, B.K. 2004. Contamination of liquid milk and butter with pesticide residues in the Ludhiana district of Punjab state, India. Ecotoxicol. Environ. Saf., 59(3): 324-331.

Bedi, J.S., Gill, J.P.S., Aulakh, R.S. and Kaur, P. 2015. Pesticide residues in bovine milk in Punjab, India: spatial variation and risk assessment to human health. Arch. Environ. Contam. Toxicol., 69(2): 230-240.

Bhuvaneshwari, R., Lavanya, N., Govindaraj, S. and Rajendran, R.B. 2015. GC-MS Determination of organochlorine pesticides in bovine milk from Tiruchirappalli, South India-a preliminary assessment. Int. J. Appl. Biol. Pharm., 6(3): 99103.

Castilla-Pinedo, Y., Alvis-Estrada, L. and Alvis-Guzmán, N.2010. Exposición a órganoclorados por ingesta de leche pasteurizada comercializada en Cartagena. Colombia. Rev. Salud. Publica., 12(1): 14-26.

Chandra, S., Mahindrakar, A.N. and Shinde, L.P. 2010. Determination of cypermethrin and chlorpyrifos in vegetables by GC-ECD. Int. J. Chem. Tech. Res., 2(2): 908-911.

Feo, M.L., Ginebreda, A., Eljarrat, E. and Barceló, D. 2010. Presence of pyrethroid pesticides in water and sediments of Ebro River Delta. J. Hydrol., 393(3-4): 156-162.

Goulart, S.M., de Queiroz, M.E.L., Neves, A.A. and de Queiroz, J.H. 2008. Low-temperature clean-up method for the determination of pyrethroids in milk using gas chromatography with electron capture detection. Talanta., 75(5): 1320-1323.

Hassanzadeh, N., Bahramifar, N. and Esmaili-Sari, A. 2010. Residue content of carbaryl applied on greenhouse cucumbers and its reduction by duration of a pre-harvest interval and post-harvest household processing. J. Sci. Food Agric., 90(13): 2249-2253.

Karabasanavar, N.S., Singh, S.P. and Singh, M.K. 2012. Monitoring for chlorpyrifos residues in animal feed and fodder of Tarai region of Uttarakhand, India. Toxicol. Environ. Chem., 94(2): 275-280.

Mostafalou, S. and Abdollahi, M. 2013. Pesticides and human chronic diseases: Evidences, mechanisms, and perspectives. Toxicol. Appl. Pharm., 268(2): 157-77. 
Nag, S.K. and Raikwar, M.K. 2008. Organochlorine pesticide residues in bovine milk. Bull. Environ. Contam. Toxicol., 80(1): 5-9.

NDDB (National Dairy Development Board) Anand. 2015. Per capita availability of milk by states (gm/day). Available at http://www.nddb.org/information/stats/percapitavail.html

Padhy, R.N. and Shakti, R.A.T.H. 2015. Probit analysis of carbamate-pesticide-toxicity at soil-water interface to N2fixing cyanobacterium Cylindrospermum sp. Rice Sci., 22(2): 89-98.

Pandit, G.G. and Sahu, S.K. 2002. Assessment of risk to public health posed by persistent organochlorine pesticide residues in milk and milk products in Mumbai, India. J. Environ. Monit., 4(1):182-185.

Rai, A., Ahmad, A., Singh, S.P., Hore, S. and Sharma, L. 2008. Detection of carbaryl residue by HPLC in foods of plant and animal origin in Kumaon region of Uttarakhand. Toxicol. Inter., 15(2): 103-109.

Shaker, E.M. and Elsharkawy, E.E. 2015. Organochlorine and organophosphorus pesticide residues in raw buffalo milk from agro-industrial areas in Assiut, Egypt. Environ. Toxicol. Pharmacol., 39(1): 433-440.
Sharma, H.R., Kaushik, A. and Kaushik, C.P. 2007. Pesticide residues in bovine milk from a predominantly agricultural state of Haryana, India. Environ. Monit. Assess., 129(1-3): 349-357.

Sun, J.F., Liu, P., Li, C.Y., Li, J.X., Wang, C.N., Min, J. and Wu, Y.N. 2011. Probabilistic acute dietary exposure assessment of the chinese population to cypermethrin residues. Food. Addit. Contam. Part A., 28(7): 869-876.

USEPA (United States Environmental Protection Agency). 2009. The value of country working together to regulate pesticides and food safety - Achieving public health and environmental protection through international collaboration. Available via http://www.epa.gov/oppfead1/international/2009/working together.pdf.

USEPA (United States Environmental Protection Agency). 2011. Exposure factor handbook, National Center for Environmental Assessment, Washington, DC, USA. 
